\title{
The influence of spirituality on decision- making in palliative care outpatients: a cross-sectional study
}

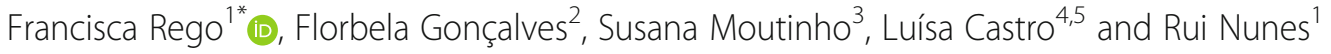

\begin{abstract}
Background: Decision-making in palliative care can be complex due to the uncertain prognosis and general fear surrounding decisions. Decision-making in palliative care may be influenced by spiritual and cultural beliefs or values. Determinants of the decision-making process are not completely understood, and spirituality is essential for coping with illness. Thus, this study aims to explore the influence of spirituality on the perception of healthcare decision-making in palliative care outpatients.

Methods: A cross-sectional study was developed. A battery of tests was administered to 95 palliative outpatients, namely: sociodemographic questionnaire (SQ), Decisional Conflict Scale (DCS), Functional Assessment of Chronic Illness Therapy-Spiritual Well-Being scale (FACIT-Sp), and a semi-structured interview (SSI) to study one's perception of spirituality and autonomy in decision-making. Statistical analyses involved descriptive statistics for SQ and SSI. The Mann-Whitney test was used to compare scale scores between groups and correlations were used for all scales and subscales. The analysis of patients' definitions of spirituality was based on the interpretative phenomenological process.

Results: Spiritual wellbeing significantly correlated with greater levels of physical, emotional and functional wellbeing and a better quality of life. Greater spiritual wellbeing was associated with less decisional conflict, decreased uncertainty, a feeling of being more informed and supported and greater satisfaction with one's decision. Most patients successfully implemented their decision and identified themselves as capable of early decision-making. Patients who were able to implement their decision presented lower decisional conflict and higher levels of spiritual wellbeing and quality of life. Within the 16 themes identified, spirituality was mostly described through family. Patients who had received spiritual care displayed better scores of spiritual wellbeing, quality of life and exhibited less decisional conflict. Patients considered spirituality during illness important and believed that the need to receive spiritual support and specialised care could enable decision-making when taking into consideration ones' values and beliefs.
\end{abstract}

Conclusion: The impact of spiritual wellbeing on decision-making is evident. Spirituality is a key component of overall wellbeing and it assumes multidimensional and unique functions. Individualised care that promotes engagement in decision-making and considers patients' spiritual needs is essential for promoting patient empowerment, autonomy and dignity.

Keywords: Autonomy, Decision-making, Decisional conflict, Palliative care, Spirituality, Spiritual wellbeing

\footnotetext{
* Correspondence: mfrego@med.up.pt

${ }^{1}$ Faculty of Medicine, University of Porto, Alameda Prof. Hernâni Monteiro,

4200-319 Porto, Portugal

Full list of author information is available at the end of the article
}

(c) The Author(s). 2020 Open Access This article is distributed under the terms of the Creative Commons Attribution 4.0 International License (http://creativecommons.org/licenses/by/4.0/), which permits unrestricted use, distribution, and reproduction in any medium, provided you give appropriate credit to the original author(s) and the source, provide a link to the Creative Commons license, and indicate if changes were made. The Creative Commons Public Domain Dedication waiver (http://creativecommons.org/publicdomain/zero/1.0/) applies to the data made available in this article, unless otherwise stated. 


\section{Background}

Palliative care is a patient-centred, transcultural and holistic approach that is essential to address the patient as a whole. In order to understand the multifaceted experience of suffering, Cicely Saunders developed the concept of total pain, which encompasses the physical, social, psychological and spiritual dimensions of end of life patients [1]. The biopsychosocial-spiritual model was also developed as an expansion upon the biopsychosocial model, which considers the spiritual concerns of patients and makes healthcare professionals aware of the need to attend these issues $[2,3]$.

Spirituality is a significant dimension of quality of life along with physical and psychological wellbeing in palliative care patients [4-6]. It is common for end of life patients to explore his or her spirituality [7]. However, the lack of agreement on the conceptualisation of spirituality in both research and clinical practice often results in a non-systematic and intuitive approach to patients' spiritual needs [7-10].

Spirituality can be envisioned as existential and/or religious $[8,11]$. Essentially, spirituality is defined as a 'way individuals seek and express meaning and purpose and the way they experience their connectedness to the moment, to [the] self, to others, to nature and to the significant or sacred' [12]. Religion can be thought of as an organised system of beliefs, practices and ways of worship [13]. Although religion may be a way to express spirituality, some individuals focus less on the spiritual aspects of religion and more on the traditions, social interactions and rituals [14]. In this way, spirituality and religion are multidimensional concepts that can co-exist in the same framework, but are also considered distinctive phenomena [15-17].

Health beliefs are related to a person's cultural background and spiritual or religious affiliations [18]. Patients' perceptions and experiences of illness, care and death are influenced by their culture, values, beliefs, life experiences and perceived meaning in life [15]. In palliative care contexts, illness-related concerns, social or externally mediated factors and psychological and spiritual considerations impact the preservation of one's sense of dignity for which a sense of autonomy and self-perception emerge as mediators $[19,20]$.

Autonomy can be related to the capacity for decisionmaking as well as functional capacity [21]. Furthermore, palliative care patients' perception of autonomy may be described as a sense of freedom along with having the right to make his or her own decisions [22].

End of life choices may reflect the meaning of life, unfinished business and planning for one's final days. Palliative care patients' decision-making may be influenced by religious, spiritual and existential beliefs, expectations, values and experiences, as well as a sense of personal meaning and satisfaction in life. Cultural factors are also inherent because cultural expectations, traditions and personal characteristics impact end of life decisions [23]. Furthermore, as patients near the end of life, the nature and impact of these personal values may change as well as the decisions he or she needs to make [24-27].

The advantages of involving patients in their own care includes improved patient communication, satisfaction and enhanced dignity [28]. However, failure to discuss and understand patient preferences in end of life care may lead to unnecessary pain, suffering and an excessive use of resources [25].

In palliative care, patients face multiple and complex decisions that, together with the physical, psychosocial and spiritual distress that often accompany the lifethreatening illness process, can lead to decisional conflict $[29,30]-$ a state of uncertainty about a specific course of action, feeling uninformed and unsupported, lack of clarity of personal values and beliefs and dissatisfaction with choice [31, 32] - and thus, influence patients' end of life experience and wellbeing [29]. Therefore, this study aims to explore the influence of spirituality on healthcare decision-making in palliative care outpatients, particularly by analysing patients' personal perceptions of decisional conflict and the relationship to spiritual wellbeing and, by exploring patients' perceptions of spirituality and autonomy in healthcare decision-making.

\section{Methods}

A cross-sectional study, quantitative methodology and interpretative description was developed. For the computation of the minimum sample size, the primary outcome considered was the assessment of the correlation between the two scales measuring decisional conflict and spiritual wellbeing administered to the sample. For a medium effect size $(d=0.3)$, a power of 0.8 and a significance level of 0.05 , a minimum of 84 participants is required [33].

A battery of tests was administered to outpatients of two palliative care services from two reference oncology institutes from March 2018 to May 2019, consecutively.

Scoring was performed face-to-face by the same interviewer, in real time, using the assessments, and all questions were read aloud due to educational or health conditions that made it difficult for subjects to fill out paper forms. Patients could choose to be alone or accompanied during the administration. The records did not contain information that could identify the participants.

Participant selection criteria included outpatients from the palliative care programmes, the ability to speak the native language and sufficient cognitive abilities to understand the questions. Subjects in a vulnerable state, or who lacked the ability to understand the administered 
questionnaires and/or who could not provide informed consent, were excluded.

This study complied with all ethical guidelines for human experimentation stated in the Helsinki Declaration.

For statistical data analysis, the Statistical Package for the Social Sciences (SPSS ${ }^{\circ}$ version 25 was used. Descriptive statistics using the median and interquartile range, median [IQR], frequencies and percentages, $n(\%)$, were used for analysis of quantitative and categorical variables, respectively. Comparison of quantitative variables between groups was done using non-parametric MannWhitney rank sum test. Pearson correlation was computed for normally distributed variables and Spearman correlation otherwise. A significance level of 0.05 was pre-determined. This study is exploratory in nature, hence no adjustment for multiple testing was performed [34].Therefore, some findings could be due to chance.

The analysis of the spirituality themes was influenced by the interpretative phenomenological approach. Median and interquartile range, median [IQR], and percentages, n (\%), were used to analyse the semi-structured interview results and compare with the scores of the DCS total score and FACIT-Sp total score and SPS subscale.

\section{Instruments \\ Informed consent and information document to the participant}

All documents made available for the participants complied with the policy of the Ethics Committee of each institution.

\section{Sociodemographic questionnaire (SQ)}

This survey was designed to collect sociodemographic characteristics - such as gender, age, marital status, education, professional status, household and religion - and clinical information - such as diagnosis, the anatomical location of the disease, time since diagnosis, treatments performed and first palliative care consultation.

\section{Semi-structured interview (SSI)}

It aimed to collect qualitative and quantitative information about how patients defined their own spirituality, the importance of spirituality during illness, spiritual care, the influence of illness in the sense/meaning of life and the ability to make decisions related to health. This semi-structured interview included closed-ended questions: sense of meaning in life, is spirituality important during illness, did sense/meaning of life change with diagnosis, previously received spiritual support, perceived capacity to make health decisions and early decision-making and if decision-making in health would be facilitated through specialised care that considered one's values and beliefs. Four short-answer questions were also included: description of one's spirituality, how is spirituality important during illness, how did sense of meaning in life change with illness and most suitable person to give spiritual support. This interview was performed due to the scarcity of data on the personal experience/meaning and opinion of patients regarding his or her own spirituality and decision-making in this context. It was developed based on a culturally validated end of life questionnaire directed to palliative care patients spirituality [35]. The English translated version is presented in the Supplementary material.

\section{Decisional conflict scale (DCS)}

This scale was composed of 16 self-completed items and five subscales, scored from 0 (strongly agree) to 4 (strongly disagree). It measures personal perceptions of decisional conflicts of patients in healthcare, namely: a) uncertainty in choosing options; b) factors contributing to uncertainty, such as feeling informed, understanding the benefits and risks and having support in decisionmaking; c) effective decision-making, such as the perception that the choice was informed and values-based and feeling satisfaction with choice [31, 32]. Total scores range from 0 to 100 and, in both the total score and subscales, a higher score indicates greater decisional conflict. A cut-off point may be used such that scores lower than 25 are associated with implementing decisions, and scores exceeding 37.5 are associated with decision delay or feeling unsure about implementation [36]. A translated and cultural-adapted version already validated was used in this study [31].

Internal consistency was examined in our sample by calculating the Cronbach's alpha coefficient for the total scale $(\alpha=0.847)$ and for subscales, ranging from 0.415 to 0.933 (Table 1).

\section{Functional assessment of chronic illness therapy - spiritual well-being (FACIT - Sp)}

This scale, which is widely used to measure healthrelated quality of life, is composed of 39 items. Each item was rated from 0 (not at all) to 4 (very much) in five domains: Physical Well-being (PWB), including reports of physical symptoms; Functional Well-being (FWB), including an analysis of the degree of participation in and experience of daily activities; Social/Familial Well-being (SWB), including an assessment of social support and communication; Emotional Well-being (EWB), including measurement of mood and emotional experience of illness; and Spiritual Well-being (SPS), which comprises Meaning/Peace and Faith subscales [37]. FACIT-Sp was developed to address spiritual wellbeing in a broader sense by focusing on existential aspects and faith. This scale is not limited to religious or spiritual traditions [16, 38]. A translated and cultural- 
Table 1 Internal consistency and descriptive statistics for the DCS $(N=95)$

\begin{tabular}{lllllll}
\hline & Cronbach's alpha & Minimum & Maximum & Median & IQR & Range \\
\hline Uncertainty & 0.508 & 25.00 & 75.00 & 41.67 & {$[25.00,50.00]$} & $0-100$ \\
Informed & 0.831 & 0.00 & 75.00 & 50.00 & {$[33.33,75.00]$} & $0-100$ \\
Values Clarity & 0.933 & 8.33 & 75.00 & 33.33 & {$[25.00,50.00]$} & $0-100$ \\
Support & 0.415 & 16.67 & 66.67 & 25.00 & {$[25.00,41.67]$} & $0-100$ \\
Effective Decision & 0.470 & 12.50 & 68.75 & 31.25 & {$[25.00,37.50]$} & $0-100$ \\
DCS total score & 0.847 & 16.00 & 41.00 & 24.00 & {$[19.00,30.00]$} & $0-100$ \\
\hline
\end{tabular}

DCS Decisional Conflict Scale

adapted version already validated for Portuguese patients was used in this study [38]. The four domains (PWB, FWB, SWB, EWB) constitute the FACT-G subscale, which represents general quality of life. And, a high score on the FACIT-Sp (PWB, FWB, SWB, EWB and SPS) is considered to correlate with improved wellbeing [39]. In this study, an internal consistency of 0.873 was observed for the total scale, for each subscale it ranged from 0.613 to 0.835 (Table 2).

\section{Results}

The sample was composed of 95 palliative care outpatients. Participants were recruited from palliative outpatient consultations of two Portuguese Institutes of Oncology, namely from the Northern Region (NOI) $(n=$ 53) and Central Region (COI) $(n=42)$ (Table 3). Participants selection was made previously, together with the liaison element of the respective institution, which had prior knowledge of each case, in order to select patients who met the desired criteria. All patients approached agreed to participate in the study, but two patients interrupted the administration of the questionnaires due to unexpected pain/symptoms.

Forty-eight were female (50.5\%), and the median age was 74 years old with a minimum age of 35 and a maximum age of 93. All patients except one reported having family members present for support with a median number of three members (Table 3).
Most participants were married (64.2\%), had elementary education (63.2\%) and were retired (69.5\%). The northern region was represented by $51.6 \%$ of the subjects, the central region by $46.2 \%$ and the south region by $2.2 \%$. The majority claimed to be religious $(94.7 \%)$, and $54.4 \%$ actively practiced their respective religion. Most patients (94.4\%) in this study were catholic (Table $3)$.

All subjects had received a cancer diagnosis, and the most common type of cancer was gastrointestinal (35.8\%). Most participants were submitted to treatments or invasive procedures (84.2\%), and the most common treatment was chemotherapy $(54.7 \%)$. The median follow-up time from diagnosis to the time of admission to the palliative care programme was 21 months (Table 4).

\section{Decisional conflict scale}

Using a cut-off point of $<25$ in the total score for decision implementation, 56 participants $(58.95 \%)$ were able to implement their decision. Using the total score cutoff of $\geq 37.5$, three subjects $(3.16 \%)$ were uncertain about their decision.

Positive significant correlations were found among all subscales with the exception of the Support subscale with the Informed and Values Clarity subscales. In other words, in this sample, there was no significant relationship between feeling supported in decision-making and

Table 2 Internal consistency and descriptive statistics for the - FACIT-Sp scale $(N=95)$

\begin{tabular}{|c|c|c|c|c|c|c|}
\hline & Cronbach's alpha & Minimum & Maximum & Median & IQR & Range \\
\hline PWB & 0.615 & 7.00 & 27.00 & 18.00 & {$[15.00,22.00]$} & $0-28$ \\
\hline SWB & 0.613 & 8.00 & 28.00 & 18.00 & {$[15.17,20.00]$} & $0-28$ \\
\hline EWB & 0.762 & 4.00 & 23.00 & 16.00 & {$[12.00,18.00]$} & $0-24$ \\
\hline FWB & 0.720 & 2.00 & 23.00 & 13.00 & {$[9.00,16.00]$} & $0-28$ \\
\hline FACT-G & 0.813 & 37.67 & 92.50 & 64.17 & {$[56.00,71.00]$} & $0-108$ \\
\hline Meaning/Peace & 0.767 & 8.00 & 26.00 & 21.00 & {$[18.00,24.00]$} & $0-32$ \\
\hline Faith & 0.725 & .00 & 14.00 & 9.00 & {$[7.00,11.00]$} & $0-16$ \\
\hline SPS & 0.835 & 8.00 & 40.00 & 31.00 & {$[25.00,34.00]$} & $0-48$ \\
\hline TOTAL & 0.873 & 49.00 & 132.50 & 93.00 & {$[83.00,104.00]$} & $0-156$ \\
\hline
\end{tabular}

FACIT - Sp Functional Assessment of Chronic Illness Therapy - Spiritual Well-Being 
Table 3 Sociodemographic characteristics

\begin{tabular}{|c|c|c|c|c|}
\hline & & Oncology Institu & & Total \\
\hline & & $\begin{array}{l}\text { Northern (NOI) } \\
n=53\end{array}$ & $\begin{array}{l}\text { Central (COI) } \\
n=42\end{array}$ & \\
\hline & & Median [IQR] & Median [IQR] & Median [IQR] \\
\hline Age (years) & & $72[60,79]$ & $74[59,80]$ & $74[60,80]$ \\
\hline $\mathrm{N}^{\circ}$ family members & & $3[2,4]$ & $3[2,3]$ & $3[2,4]$ \\
\hline & & n (\%) & n (\%) & n (\%) \\
\hline Gender & Female & $32(60.4)$ & $16(38.1)$ & $48(50.5)$ \\
\hline & Male & 21 (39.6) & $26(61.9)$ & 47 (49.5) \\
\hline Marital status & Single & $5(9.4)$ & $5(11.9)$ & $10(10.5)$ \\
\hline & Married & $35(66)$ & $26(61.9)$ & $61(64.2)$ \\
\hline & Divorced & $3(5.7)$ & $2(4.8)$ & $5(5.3)$ \\
\hline & Widow & $10(18.9)$ & $8(19)$ & $18(18.9)$ \\
\hline & Cohabitation & 0 & $1(2.4)$ & $1(1.1)$ \\
\hline Location & North region & $48(94.1)$ & 0 & $48(51.6)$ \\
\hline & Central region & $3(5.9)$ & $40(95.2)$ & $43(46.2)$ \\
\hline & South region & 0 & $2(4.8)$ & $2(2.2)$ \\
\hline Education & No studies & $11(20.8)$ & 12 (28.6) & $23(24.2)$ \\
\hline & $<$ high school & $34(64.2)$ & $26(61.9)$ & $60(63.2)$ \\
\hline & High school & $6(11.3)$ & $2(4.8)$ & $8(8.4)$ \\
\hline & Graduate & $2(3.8)$ & $2(4.8)$ & $4(4.2)$ \\
\hline Professional status & Retired & 39 (73.6) & $27(64.3)$ & 66 (69.5) \\
\hline & Homemaker & $2(3.8)$ & $3(7.1)$ & $5(5.3)$ \\
\hline & Employed & $1(1.9)$ & $2(4.8)$ & $3(3.2)$ \\
\hline & Unemployed & 0 & $2(4.8)$ & $2(2.1)$ \\
\hline & Disability status & $11(20.8)$ & $8(19)$ & $19(20)$ \\
\hline Religious & Yes & $52(98.1)$ & $38(90.5)$ & $90(94.7)$ \\
\hline & No & $1(1.9)$ & $4(9.5)$ & $5(5.3)$ \\
\hline & & $n=52$ & $n=38$ & $n=90$ \\
\hline Religious practice & Yes & $34(65.4)$ & $15(39.5)$ & $49(54.4)$ \\
\hline & No & $18(34.6)$ & $23(69.5)$ & $41(45.6)$ \\
\hline Religion type & Catholic & $48(92.3)$ & 37 (97.4) & $85(94.4)$ \\
\hline & Christian & $1(1.9)$ & 0 & $1(1.1)$ \\
\hline & Jehovah's Witness & $1(1.9)$ & $1(2.6)$ & $2(2.2)$ \\
\hline & Spirituality & $1(1.9)$ & 0 & $1(1.1)$ \\
\hline & UCKG & $1(1.9)$ & 0 & $1(1.1)$ \\
\hline
\end{tabular}

feeling informed and clear about personal values for the benefits and risks/side effects. A weaker but significant relationship between support and effective decisionmaking was found (Table 5).

\section{FACIT-Sp}

Regarding participants' spiritual wellbeing, the score for the Spiritual Wellbeing (SPS) and Meaning/Peace subscales displayed a significant positive correlation with all FACIT-Sp subscales with the exception of the social wellbeing (SWB) subscale. The Faith subscale showed a significant and positive correlation for the EWB, FWB, FACT-G and Meaning/Peace subscales (Table 6).

\section{DCS and FACIT-Sp}

Patients who were able to implement their decision $(n=56$, DCS total score $<25$ ), compared with the remaining 39 participants who scored $\geq 25$, showed significantly higher scores on the EWB ( $\mathrm{U}=699 ; p=0.001)$, FACT-G $(\mathrm{U}=792.5 ; p=$ 0.012), Meaning/Peace $(\mathrm{U}=681 ; p=0.001)$, Faith $(\mathrm{U}=813$; 
Table 4 Clinical Characteristics

\begin{tabular}{|c|c|c|c|c|}
\hline & & \multicolumn{2}{|c|}{ Oncology Institution } & \multirow{2}{*}{$\begin{array}{l}\text { Total } \\
N=95\end{array}$} \\
\hline & & \multirow{2}{*}{$\begin{array}{l}\text { Northern (NOI) } \\
n=53 \\
\text { Median [IQR] }\end{array}$} & \multirow{2}{*}{$\begin{array}{l}\text { Central (COI) } \\
n=42 \\
\text { Median [IQR] }\end{array}$} & \\
\hline & & & & Median [IQR] \\
\hline \multirow{2}{*}{\multicolumn{2}{|c|}{ Time since diagnosis until admission in palliative care (months) }} & $21[14,48]$ & $17.5[7,42]$ & $21[9,48]$ \\
\hline & & $n(\%)$ & $n(\%)$ & $n(\%)$ \\
\hline Diagnosis & Cancer & $53(100)$ & $42(100)$ & $95(100)$ \\
\hline \multirow[t]{2}{*}{ Cancer Diagnosis } & One site & $53(100)$ & $42(100)$ & $95(100)$ \\
\hline & Two or more sites & $3(5.7)$ & $3(7.1)$ & $6(6.3)$ \\
\hline \multirow[t]{12}{*}{ Cancer Site } & Gastrointestinal & $23(43.4)$ & $11(26.2)$ & $34(35.8)$ \\
\hline & Head and neck & $3(5.7)$ & $16(38.1)$ & $19(20)$ \\
\hline & Breast & $6(11.3)$ & $5(11.9)$ & $11(11.6)$ \\
\hline & Lungs & $4(7.5)$ & $4(9.5)$ & $8(8.4)$ \\
\hline & Gynaecological & $7(13.2)$ & $1(2.4)$ & $8(8.4)$ \\
\hline & Prostate & $2(3.8)$ & $3(7.1)$ & $5(5.3)$ \\
\hline & Colorectal & $3(5.7)$ & $1(2.4)$ & $4(4.2)$ \\
\hline & Skin & $2(3.8)$ & $1(2.4)$ & $3(3.2)$ \\
\hline & Bones & $2(3.8)$ & 0 & $2(2.1)$ \\
\hline & Urinary tract & $1(1.9)$ & $1(2.4)$ & $2(2.1)$ \\
\hline & Thyroid & $1(1.9)$ & 0 & $1(1.1)$ \\
\hline & Others & $2(3.8)$ & $2(4.8)$ & $4(4.2)$ \\
\hline \multirow[t]{2}{*}{ Treatments/Procedures } & Yes & $47(88.7)$ & 33 (78.6) & $80(84.2)$ \\
\hline & No & $6(11.3)$ & $9(21.4)$ & $15(15.8)$ \\
\hline \multirow[t]{7}{*}{ Treatment/Procedure Type } & Chemotherapy & $33(62.3)$ & $19(45.2)$ & $52(54.7)$ \\
\hline & Radiotherapy & $18(34)$ & $22(52.4)$ & $40(42.1)$ \\
\hline & Hormonotherapy & $1(1.9)$ & $1(2.4)$ & $2(2.1)$ \\
\hline & Immunotherapy & 0 & $3(7.1)$ & $3(3.2)$ \\
\hline & Surgery & $27(50.9)$ & $13(31.0)$ & $40(42.1)$ \\
\hline & Tracheostomy & $1(1.9)$ & $4(9.5)$ & $5(5.3)$ \\
\hline & Others & $1(1.9)$ & $3(7.1)$ & $4(4.2)$ \\
\hline
\end{tabular}

$p=0.017)$ and SPS $(\mathrm{U}=692.5 ; p=0.001)$ subscales, as well as on the FACIT-Sp total scale $(\mathrm{U}=755.5 ; p=0.005)$. Only 3 patients were unable to implement their decision or were uncertain about their decision (DCS total score $\geq 37.5$ ).

Significant negative correlations were found among several subscales of the DCS and subscales and SPS FACIT-Sp subscale. Higher spiritual wellbeing was found significantly associated with lower levels of uncertainty, feeling informed and supported, higher satisfaction with the choice made and lower decisional conflict (Table 7). Strong significant correlations were also found for higher emotional wellbeing and quality of life and lower levels of uncertainty and decisional conflict (Table 7).

Table 5 Spearman's correlations between DCS subscales $(N=95)$

\begin{tabular}{|c|c|c|c|c|c|}
\hline & Uncertainty & Informed & Values Clarity & Support & Effective Decision \\
\hline Uncertainty & & $0.303^{* *}$ & $0.382^{* *}$ & $0.366^{* *}$ & $0.374^{* *}$ \\
\hline Informed & & & $0.661^{* *}$ & 0.077 & $0.554^{* *}$ \\
\hline Values Clarity & & & & 0.156 & $0.577^{* *}$ \\
\hline Support & & & & & $0.241^{*}$ \\
\hline
\end{tabular}

${ }^{*} p<0.05 ;{ }^{* *} p<0.01$ 
Table 6 Spearman's correlations between FACIT-Sp subscales $(N=95)$

\begin{tabular}{|c|c|c|c|c|c|c|c|}
\hline & PWB & SWB & EWB & FWB & Meaning/Peace & Faith & SPS \\
\hline PWB & & 0.148 & $0.455^{* *}$ & $0.508^{* *}$ & $0.371^{* *}$ & 0.113 & $0.281^{* *}$ \\
\hline SWB & & & 0.042 & $0.252^{*}$ & 0.049 & 0.044 & 0.040 \\
\hline EWB & & & & $0.492^{* *}$ & $0.635^{* *}$ & $0.382^{* *}$ & $0.597^{* *}$ \\
\hline FWB & & & & & $0.462^{* *}$ & $0.298^{* *}$ & $0.446^{* *}$ \\
\hline FACT-G & & & & & $0.554^{* *}$ & $0.296^{* *}$ & $0.494^{* *}$ \\
\hline Meaning/Peace & & & & & & $0.508^{* *}$ & \\
\hline
\end{tabular}

${ }^{*} p<0.05 ;{ }^{* *} p<0.01$

\section{Semi-structured interview}

Data collected during the interviews enabled the analysis of 95 significant statements concerning the description of patients' spirituality. The analysis was influenced by the interpretative phenomenological approach, in which the researchers made an interpretation of the meaning of the lived experiences of the patients [40]. The authors independently found expressions, which were then compared. This allowed to make theoretical connections, still reflecting the particularity of each experience [40]. This process enabled the authors to reach a total of 16 consensual themes. The most frequent spirituality topic mentioned was 'Family', followed by 'God/Religion', by 51.6 and $30.5 \%$ of the participants, respectively (Table 8 ).

This research aimed to study the relationship between spirituality and patient decision-making. Thus, the median scores of the SPS FACIT-Sp subscale, DCS and FACIT-Sp from the groups that answered 'yes' or 'no' in the semi-structured closed-ended questions were analysed. The 'don't know' group wasn't comprised given the small number of answers.

Participants who asserted the importance of spirituality during their illness process $(n=85,89.5 \%)$, mainly due to strength $(n=22,25.9 \%)$ and support $(n=20,23.5 \%)$, indicated higher scores of spiritual wellbeing (median $[\mathrm{IQR}]=32[26,34]$ vs $23[15,29]$ ) and quality of life $(97[85,106]$ vs $80.4[57.8,98])$, and lower decisional conflict $(24[19,30]$ vs 31 [19, 37]) (Table 9).

'Sense of meaning in life' was noted by most subjects ( $n=64,67.4 \%$ ); however, 22 participants (23.2\%) stated that they did not have a sense of meaning in life, and nine participants $(9.5 \%)$ did not know if their lives still had any meaning. Considerably higher scores of spiritual wellbeing $(32[28.5,35]$ vs $20[18,30])$ and quality of life $(100[90,108]$ vs $74.2[64.7,85])$ were found for participants who had a sense of meaning in life, as well as lower levels of decisional conflict $(23.5$ [19, 29] vs 28 [18, 32]) (Table 9).

Most participants $(n=70,73.7 \%)$ stated that their sense/meaning of life changed with illness, mainly because of physical limitations $(n=34,48.6 \%)$ and the loss of autonomy $(n=33,47.1 \%)$. Although the differences in score were not very prominent, patients whose sense of meaning in life didn't change with the illness presented higher quality of life scores $(101[93.8,111]$ vs 90.3 [80.7, 101.7]) (Table 9).

The majority of participants stated not receiving any spiritual care or support during their illness $(n=72$, $75.8 \%)$. Moreover, patients indicated that the most suitable people to provide this kind of support were family members $(n=29,40.3 \%)$ particularly, a spouse $(n=11$, $37.9 \%)$; healthcare professionals $(n=11,15.3 \%)$, such as psychologists $(n=4,36.4 \%)$ and medical doctors $(n=3$,

Table 7 Spearman's correlations between FACIT-Sp and DCS scales and subscales

\begin{tabular}{|c|c|c|c|c|c|c|}
\hline \multirow[t]{2}{*}{ FACIT-Sp } & \multicolumn{6}{|l|}{ DCS } \\
\hline & Uncertainty & Informed & Values Clarity & Support & Effective Decision & Total Score \\
\hline PWB & $-0.221 *$ & -0.10 & -0.081 & -0.096 & -0.104 & -0.117 \\
\hline SWB & -0.044 & -0.058 & -0.066 & -0.038 & -0.096 & -0.078 \\
\hline EWB & $-0.313^{* *}$ & -0.199 & $-0.245^{*}$ & -0.201 & $-0.207^{*}$ & $-0.307^{* *}$ \\
\hline FWB & $-0.214^{*}$ & -0.194 & -0.199 & -0.014 & -0.155 & $-0.230^{*}$ \\
\hline FACT-G & $-0.265^{* *}$ & -0.170 & -0.200 & -0.133 & -0.184 & $-0.250^{*}$ \\
\hline Meaning/Peace & $-0.277^{* *}$ & $-0.250^{*}$ & -0.158 & $-0.273^{* *}$ & $-0.211^{*}$ & $-0.287^{* *}$ \\
\hline Faith & -0.210 & -0.176 & -0.150 & -0.191 & $-0.263^{*}$ & $-0.275^{* *}$ \\
\hline SPS & $-0.267^{* *}$ & $-0.237^{*}$ & -0.177 & $-0.269 * *$ & $-0.262^{*}$ & $-0.326^{* *}$ \\
\hline FACIT-Sp Total & $-0.286^{* *}$ & -0.186 & -0.201 & -0.190 & $-0.224^{*}$ & $-0.284^{* *}$ \\
\hline
\end{tabular}

${ }^{*} p<0.05 ;{ }^{* *} p<0.01$ 
Table 8 Descriptions of patients' spirituality

\begin{tabular}{|c|c|c|}
\hline Topics & $N=95(\%)$ & Example \\
\hline Family & 49 (51.6) & $\begin{array}{l}\text { 'My family' } \\
\text { 'Family that I love and support' }\end{array}$ \\
\hline God/Religion & $29(30.5)$ & $\begin{array}{l}\text { 'God gives me courage' } \\
\text { 'Jesus Christ is our salvation' }\end{array}$ \\
\hline To live & $16(16.9)$ & $\begin{array}{l}\text { 'Will to live' } \\
\text { 'I think about living' }\end{array}$ \\
\hline Faith & $11(11.6)$ & 'Faith' \\
\hline Inner strength & $11(11.6)$ & $\begin{array}{l}\text { 'Courage inside me' } \\
\text { 'To face good and evil' }\end{array}$ \\
\hline World & $9(9.5)$ & 'To see the world"society, travel ...' \\
\hline Friends & $7(7.4)$ & $\begin{array}{l}\text { 'To hang out with friends ...' } \\
\text { 'Neighbours ...' }\end{array}$ \\
\hline Basic needs & $7(7.4)$ & $\begin{array}{l}\text { 'Be able to eat ...' } \\
\text { 'Walk again ...' }\end{array}$ \\
\hline Work & $7(7.4)$ & $\begin{array}{l}\text { 'My profession, I feel useful' } \\
\text { 'A working man' }\end{array}$ \\
\hline Autonomy & $6(6.3)$ & $\begin{array}{l}\text { 'Have strength to do what I did before' } \\
\text { 'Have a normal life again ...' }\end{array}$ \\
\hline Hope & $6(6.3)$ & 'Have hope' \\
\hline Healing/Health & $5(5.3)$ & 'I want to heal myself'It's health!' \\
\hline Nature & $4(4.2)$ & $\begin{array}{l}\text { 'The mountain air ...' } \\
\text { 'Gardening and taking care of my chickens' }\end{array}$ \\
\hline Believe & $4(4.2)$ & 'To believe' \\
\hline Suffering & $4(4.2)$ & $\begin{array}{l}\text { 'It's a sacrifice. I don't have the will to live. The faster this is settled, the better' } \\
\text { 'I would like to join my husband, he passed away less than a year ago ...' }\end{array}$ \\
\hline Superior forces & $3(3.2)$ & 'Some superior force ...' 'Destiny, I have this, and I have to face it' \\
\hline
\end{tabular}

Table 9 Median scores of the DSC, FACIT-Sp and SPS subscale according to participants' answers on the close-ended questions on the semi-structured interview

\begin{tabular}{|c|c|c|c|c|}
\hline \multicolumn{2}{|l|}{ Semi-structured interview } & \multirow{2}{*}{$\begin{array}{l}\text { DCS total score } \\
\text { Median }[\mathrm{IQR}] \\
24[19,30]\end{array}$} & \multirow{2}{*}{$\begin{array}{l}\text { SPS FACIT-Sp } \\
\text { Median [IQR] } \\
32[26,34]\end{array}$} & \multirow{2}{*}{$\begin{array}{l}\text { FACIT-Sp total score } \\
\text { Median }[\mathrm{IQR}] \\
97[85,106]\end{array}$} \\
\hline 1. Importance of spirituality during illness & yes $(n=85)$ & & & \\
\hline & no $(n=6)$ & $31[19,37]$ & $23[15,29]$ & $80.4[57.8,98]$ \\
\hline \multirow[t]{2}{*}{ 2. Sense of meaning in life } & yes $(n=64)$ & $23.5[19,29]$ & $32[28.5,35]$ & $100[90,108]$ \\
\hline & no $(n=22)$ & $28[18,32]$ & $20[18,30]$ & $74.2[64.7,85]$ \\
\hline \multirow[t]{2}{*}{ 3. Sense of meaning in life changed with illness } & yes $(n=70)$ & $24[19,31]$ & $30[25,34]$ & $90.3[80.7,4101.7]$ \\
\hline & no $(n=25)$ & $23[20,27]$ & $32[30,35]$ & $101[93.8,111]$ \\
\hline \multirow[t]{2}{*}{ 4. Spiritual support } & yes $(n=23)$ & $20[17,28]$ & $34[30,36]$ & $99[90.7,106]$ \\
\hline & no $(n=72)$ & $24[20,31]$ & $30[23,33.5]$ & $92.5[80.5,102.5]$ \\
\hline \multirow[t]{2}{*}{ 5. Capacity of decision-making } & Own decisions $(n=64)$ & $23.5[19,29.5]$ & $32[26.5,34]$ & $97.5[86.5,105.5]$ \\
\hline & Dependent on others $(n=31)$ & $24[19,32]$ & $30[22,34]$ & $90.7[81,101.7]$ \\
\hline \multirow[t]{2}{*}{ 6. Capable of early decision-making } & yes $(n=62)$ & $22[19,30]$ & $32[26,35]$ & $97[85,105]$ \\
\hline & $\mathrm{no}(n=31)$ & $25[19,32]$ & $30[22,32]$ & $91[81,101.7]$ \\
\hline \multirow[t]{2}{*}{ 7. Important to have spiritual support } & yes $(n=58)$ & $22.5[19,30]$ & $31[26,34]$ & $93.4[86,106]$ \\
\hline & no $(n=22)$ & $23.5[19,32]$ & $32.5[26,35]$ & $98.5[88,105]$ \\
\hline \multirow[t]{2}{*}{ 8. Facilitation of decision-making in health through a specialised care } & yes $(n=64)$ & $24[19,30]$ & $32[26,34]$ & $97.7[88.5,106.2]$ \\
\hline & no $(n=21)$ & $24[19,31]$ & $30[25,35]$ & $95.5[77,104]$ \\
\hline
\end{tabular}


27.3\%); Gods/saints ( $n=10,13.9 \%)$; a spiritual/religious community $(n=5,6.9 \%)$; informal caregivers/friends $(n=2,2.8 \%)$ and oriental therapies e.g. reiki $(n=1$, $1.4 \%)$. Three participants (4.2\%) responded that no one could give them support, and eight participants (11.1\%) did not know what/who could be the most suitable support system.

On the other hand, 23 subjects $(24.2 \%)$ had received spiritual support primarily from their spiritual/religious community $(n=17,73.9 \%)$, family members $(n=4$, $17.4 \%)$, specifically a spouse $(n=1,25 \%)$, and nurses $(n=1,4.3 \%)$. These subjects presented higher scores on spiritual wellbeing and quality of life for the SPS (34 [30, $36]$ vs $30[23,33.5])$ and FACIT-Sp (99 [90.7, 106] vs $92.5[80.5,102.5])$, as well as lower decisional conflict score in the DCS $(20[17,28]$ vs $24[20,31])$. Moreover, 58 participants $(61.1 \%)$ asserted the importance of receiving spiritual care, 22 participants $(23.2 \%)$ answered that they did not need this kind of care, and 15 (15.8\%) indicated 'didn't know'. Nevertheless, there were no relevant differences found in the DCS total score, FACIT-Sp total score and SPS subscale for the 'yes' and 'no' groups (Table 9).

With regard to the perceived capacity to make health decisions, 64 participants $(67.4 \%)$ claimed to be able to decide on their own, and 31 (32.6\%) indicated feeling dependent on others to make health decisions. Concerning early decision-making about their future, 62 participants $(65.3 \%)$ felt capable, 31 (32.6\%) did not feel able and two $(2.1 \%)$ did not know whether they were fit to engage in early decision-making. Participants who felt capable of making their own decisions and of early decision-making presented slightly higher scores of spiritual wellbeing and quality of life and lower scores on decisional conflict (Table 9).

Most participants $(n=64,67.4 \%)$ indicated that decision-making in health would be facilitated through specialised care that considered one's values and beliefs. On the other hand, 21 participants (22.1\%) did not consider it to be relevant, and $10(10.5 \%)$ did not know if it would be pertinent for decision-making. Subjects who found decision-making enabled through specialised care, scored slightly higher on the FACIT-Sp total score (97.7 $[88.5,106.2]$ vs $95.5[77,104])$ (Table 9).

\section{Discussion}

This study aimed to explore the relationship between spirituality and decision-making in palliative care outpatients at two oncology institutes $(n=95)$. Participants' perceptions of decision-making, in specific decisional conflict, and the connection to spirituality, particularly spiritual wellbeing, were analysed.

The DCS showed acceptable reliability and validity when used to assess decision-making related to end of life care [41]. In this study, good internal consistency was observed for both the total scale and subscales; with the exception of subscales Uncertainty, Support and Effective Decision, which displayed low internal consistency. During decision-making, uncertainty can be resolved through information-gathering; however, as a consequence, patients can perceive the decision as effective despite experiencing uncertainty [42]. The FACIT-Sp, which is one of the most common instruments used in a palliative care setting to measure quality of life in general and spiritual wellbeing in particular [6], displayed sufficient to very good internal consistency.

A homogeneous sample of men and women was obtained, with a median age of 74 years old, a minimum age of 35 and a maximum age of 93 . Studies have shown that increasing age was significantly associated with better physical, psychological and existential scores [43, 44] as well as better end of life preparation [45]. On the other hand, spiritual and quality of life outcomes are usually worse for younger patients due to the possibility of a shortened lifespan, functional deterioration and unfulfilled aspirations, which can be sources of great spiritual and psychosocial distress [46].

The majority of patients claimed to be religious, mainly catholic, in which more than half practiced their respective religion. Faith, rituals and associated prayers are also shown to influence many areas of patients' lives [47-49], such as positive emotions, quality of life and social interactions $[47,48,50]$ as well as death, disability, financial problems and one's future in as part of family [48, 50-53]. Positive religious coping is correlated with faith, which promotes health and psychological adaptation to serious illness and provides a positive spiritual support system [54-56]. The social support that results from religious engagement is a key factor, since this support system is found within faith communities and also in local neighbourhoods and service communities [57, 58].

However, when patients rely solely on a higher power for mental and physical health without any problemsolving mechanisms, it may result in poorer long-term health outcomes [53, 59]. A negative religious coping mechanism (e.g., perceiving illness as a punishment or abandonment by God) is associated with higher levels of distress, confusion and depression, in addition to a poorer sense of physical and emotional wellbeing and quality of life $[60,61]$. Furthermore, the need to conform to a particular belief system for health decision-making and a family's concerns related to religious beliefs or the importance of religious faith may result in anxiety and negative effects on health. These factors may also exacerbate the effect of family stressors on depression [62-64].

The impact of spirituality on the overall wellbeing of patients was observed in this study. Patients' who found spirituality important during illness presented higher 
scores of spiritual wellbeing, quality of life, and lower levels of decisional conflict. In addition, having a sense of meaning in life was associated with higher levels of quality of life and spiritual wellbeing, and lower levels of decisional conflict. Thus, considering spirituality during care is beneficial for terminally ill patients because it allows the evaluation of patients' spiritual wellbeing or to what extent patients' spirituality can help them make sense of their lives in order to feel whole, hopeful and peaceful $[16,65,66]$.

The main effect of illness on a patient's sense of meaning in life was mainly related to physical limitations and loss of autonomy. Patients whose sense of meaning in life did not change with illness displayed a better score of quality of life. Palliative care patients valued being able to perform daily tasks and feeling useful when appropriate [21]. Patients who feel independent may present higher levels of optimism, self-esteem, social support and spiritual wellbeing, in addition to fewer symptoms of depression [16, 67]. Late referrals to palliative care are an aspect that may complicate patient involvement in care and the promotion of autonomy. In late engagement, besides the reduced ability of the patient to participate in decision-making due to advanced illness, the decisions that remained mainly concern terminal symptom management [68].

Furthermore, significant associations among greater spiritual wellbeing and better physical, emotional and functional wellbeing, higher levels of meaning/peace and faith and a better quality of life were found. The influence of spiritual wellbeing on psychological and physical dimensions has been enhanced in most studies [51, 6971]. These results highlighted the importance of spirituality as a coping mechanism [59]. The social dimension did not show an association with spiritual wellbeing as observed in other studies [16, 72].

Patients' views on spirituality were found to be connected with family as well as related to their religious beliefs. These connections provided participants various benefits, such as meaning and purpose in life, compassion toward others and a positive spiritual influence [73-75]. Of the topics that assessed spirituality descriptions, 'Family' and 'God/religion' were the most commonly mentioned topic. The major role of one's spirituality in illness as mentioned by patients was strength and support. Furthermore, family members were described by patients as being the best-suited to provide spiritual support, followed by healthcare professionals (namely, psychologists and medical doctors). The multidimensionality of spirituality was identified as a unique and individual dimension that may be related to the self, others and the world. It can be moved by the search for meaning in life [12]. The relationship between religion and spirituality should be noted, but the roles they play may be distinct [15-17].
A relationship between spiritual wellbeing and decisional conflict was observed in this study. Higher levels of spiritual wellbeing were significantly associated with less uncertainty, feeling more informed and supported, greater satisfaction with decisions and less decisional conflict. Furthermore, strong significant associations were found between higher emotional wellbeing and quality of life and lower levels of uncertainty and decisional conflict. According to O'Connor [32], decisional conflict along with cognitive, emotional and social factors can increase a person's perception of uncertainty, which difficult decision-making. Decisional conflict may be expressed by the verbalisation of uncertainty, indecision between choices, delayed decision-making and questioning personal values and beliefs while attempting to make a decision [42]. Besides, patients in this context may feel fearful that their decisions may bring them closer to death [76].

Studies point to the impact of patients' spirituality on end of life decision-making and show that high levels of spiritual wellbeing associate with improved quality of life, disease coping, adjustment to diagnosis, the ability to cope with symptoms and protect against depression, hopelessness and the desire for a hastened death [11, 47]. This way, spirituality may help both clinicians and researchers with clinical conceptualisation and subsequent treatment planning $[16,65,66]$ given that participants who received spiritual care presented lower scores of decisional conflict and higher levels of spiritual wellbeing and quality of life. Patients who were able to implement their decisions displayed higher levels of emotional and spiritual wellbeing, greater levels of meaning/peace, more faith and a better quality of life. Patients found the decision-making process satisfactory if the process was supportive and informed such that their decision-making was consistent with their values and beliefs [41]. In this sense, spiritual wellbeing was helpful to patients coping with end of life decisions because it likely facilitated decision-making through positive coping mechanisms [77], promoting a peaceful death experience and addressing the needs of dying patients [16, 78].

The perception of making a good or bad decision may be dependent on a person's perception of illness and their global beliefs, such as identity, health and overall goals, level of distress related to his or her illness and spirituality [79]. This variance may impact the decisionmaking balance associated with benefits and risks, which may lead to doubt [76]. Healthcare professionals need to determine how the patient prefers to be included in decision-making process given that these issues are often culturally based with spiritual or religious implications [18]. Discussion of a patient's care plans (such as advanced care planning or end of life care) and the 
acknowledgement of the patient's specific demographic and clinical characteristics may help predict patients' spiritual beliefs and attitudes. These actions may provide an opportunity for patients to explore decisions with their families, enable clearer lines of communication with healthcare professionals and develop patientcentred goals [18, 27, 43].

Most participants considered it important to have spiritual care, however the majority didn't receive spiritual care. The lack of preparation and education on spirituality at the end of life may result in discomfort and, therefore, avoidance of many healthcare professionals to broach these issues [18]. It is important to promote knowledge of the importance of spirituality and how this type of support/intervention may enhance spirituality as a means of comfort and peace during life-threatening illnesses $[16,78]$.

There is a need to be familiar and respectful of traditions and beliefs and, if possible, integrate them into the care plan. A specialised care that takes into consideration one's values and beliefs was found to enable health decision-making. Thus, the need for healthcare professionals to impartially assess the needs of patients as a whole by identifying a person's values and belief system, spiritual history, distress and needs is essential for promoting dignity, autonomy and the right for the patient's self-determination [80]. As well as taking into account the specific cultural and ethical background of patients, advocacy will provide individualised and appropriate care for palliative care patients [81].

\section{Conclusions}

According to the principles of palliative care, which aim to improve patients' and their families' quality of life through the prevention and relief of pain and physical, psychosocial and spiritual suffering [5], patient dignity and autonomy are central points for improving care [22]. Autonomy is defined as the 'right of a capable person to decide his/her own course of action' [27], and has been identified as one of the four major ethical principles [82].

Most participants in this study felt capable of decisionmaking in healthcare situations as well as of early decision-making. An autonomous decision presupposes the capacity to decide, and the capacity to value one's own existence is essential for assigning personhood and moral agency [83]. The benefits of autonomy in health are reflected in the form of physical, psychological, social and spiritual wellbeing [21].

Spirituality is considered to be a unique part of everyday interactions and life [18] and it was mostly described by participants through family or God/religion. This way, it is denoted the multidimensional characteristics of spirituality. Family plays an important role in end of life search for meaning [84]. It is seen as the unit of care since it finds its own potential and enables achievements at the end of life [84]. In addition, family support that can help advocate for the patient, may decrease stress and provide end of life comfort, even if patients have the capacity to make their own health decisions [85].

Several patients related their spirituality to God/religion. Nevertheless, when beliefs are not used in an adaptive way, decision-making could be affected. Thus, palliative care teams should be alerted to signs of negative religious coping and collaborate with spiritual care workers to address the distress experienced by these patients [60].

Spirituality plays an important role at the end of life. In fact, spiritual wellbeing was associated with higher rates of physical, emotional and functional wellbeing and a better quality of life.

The influence of spiritual wellbeing on decisionmaking was evident, as participants with higher levels of spiritual wellbeing showed less uncertainty with choice, feelings of being more informed and supported, a higher level of satisfaction with decisions and less decisional conflict. Furthermore, patients who were able to implement their decisions displayed better emotional and spiritual wellbeing and an improved quality of life. Thus, it is important to consider end of life decisions in terms of patients' values, beliefs and relief of suffering [23].

Given the effects of end of life care and the difficulty and uncertainty associated with patient's choices, there is a need for methods to measure the quality of those choices [41]. Since palliative patients prefer a personcentred, individualised care approach and responsive healthcare professionals who consider their requests in counselling and treatment [86], specialised care that considers one's values and beliefs may improve overall health decision-making, as indicated by participants.

An autonomous decision indicates that patients were able to re-evaluate their lives and accept their decreasing health status and imminent death [76]. Therefore, healthcare professionals should consider spirituality as a potentially important component of every patient's physical wellbeing and mental health [87]. Specifically, they should become aware of how patients use their spirituality and/or faith to cope with their illness, which can help identify whether specialised mental health and/or religious practices would be beneficial for pain management $[59,88]$ while promoting patients' self-determination and empowerment [86]. This would enable to restore a sense of dignity, autonomy and self-worth in patients [89].

This exploratory study raises several pertinent hypotheses which should be further validated in new studies based on independent datasets [34].

To analyse the qualitative data, the interpretative phenomenological analysis process should be conducted, to 
allow a more in-depth, comprehensive and narrative analysis of the results [40]. Furthermore, the semistructured interview should be validated for the Portuguese palliative population.

In this study, the clinical data collected was based on patients' perception of their diagnosis, treatments and health status. Nevertheless, future studies should comprise the medical record of the patient, such as diagnosis and stage of the illness, criteria for palliative care transition, Palliative Performance Scale (PPS) and treatment plan. Furthermore, patient selection was made previously by a liaison element, according to the selection criteria and patients' availability, e.g. ambulance transportation schedules. Future studies should comprise all patients and record the information of the patients approached, so comparisons can be made on the differences between the patients who participate and those who do not, either due to refusal or due to the illness condition.

Moreover, future studies should explore the optimal way to address patients' spirituality and needs with respect to their clinical history [60]. Future studies should also explore the effects of promoting patients decisionmaking based on each person's unique perspective, taking into account that this process is influenced by their psychophysiological state, personal and/or professional values and beliefs, spiritual and sociocultural beliefs, needs, education and knowledge [86]. This way, the need to involve an advocate or other health professional with special expertise in cross-cultural issues and spirituality is essencial [18]. This approach will help address patients as a whole by respecting their autonomy, dignity and end of life process.

\section{Supplementary information}

Supplementary information accompanies this paper at https://doi.org/10. 1186/s12904-020-0525-3.

Additional file 1. Semi-structured interview

\begin{abstract}
Abbreviations
COI: Portuguese Institute of Oncology - Central region; DCS: Decisional Conflict Scale; EWB: Emotional Well-being subscale; FACIT-Sp: Functional Assessment of Chronic IIIness Therapy - Spiritual Well-Being; FACT-G: General Quality of life subscale; FWB: Functional Well-being subscale; NOI: Portuguese Institute of Oncology - Northern region; PWB: Physical Well-being subscale; SPS: Spiritual Well-being subscale; SQ: Sociodemographic Questionnaire; SSI: Semi-structrured Interview; SWB: Social Well-being subscale
\end{abstract}

\section{Acknowledgements}

We thank the Portuguese Institute of Oncology - Porto and Portuguese Institute of Oncology - Coimbra for their help and support in this project, especially the palliative care teams' medical doctors, nurses and staff, in the contact and communication with patients. A special thank you to all the patients and families who participated in this study.

Lastly, we would like to thank Professor Harvey Max Chochinov, University of Manitoba, for his valuable recommendations.

\section{Authors' contributions}

FR and RN contributed to the conception and design of the study. FR, SM, FG assisted for the acquisition and organisation of data and FR and LC in the organisation of the database and data analysis. FR, LC, RN contributed in the analysis and interpretation of data and revising the manuscript critically for important intellectual content. All authors read and approved the final manuscript

\section{Funding}

The authors received no funding for this study.

\section{Availability of data and materials}

The datasets used and/or analysed during the current study are available from the corresponding author on reasonable request.

\section{Ethics approval and consent to participate}

This research was approved by the two institutions, namely the Administration Counsel Portuguese Institute of Oncology - Coimbra; and the Ethics committee for health Portuguese Institute of Oncology - Porto: CES IPO: 37/2018.

All subjects were informed about the aims of the study and gave written informed consent prior to their participation and the records did not contain information that could identify the participants. This study complied with all ethical guidelines for human experimentation stated in the Helsinki Declaration.

\section{Consent for publication}

Not applicable.

\section{Competing interests}

The authors declare that they have no competing interests.

\section{Author details}

${ }^{1}$ Faculty of Medicine, University of Porto, Alameda Prof. Hernâni Monteiro, 4200-319 Porto, Portugal. ${ }^{2}$ Portuguese Institute of Oncology-Coimbra, Instituto Português de Oncologia de Coimbra Francisco Gentil, E.P.E., Av. Bissaya Barreto 98, 3000-075 Coimbra, Portugal. ${ }^{3}$ Portuguese Institute of Oncology-Porto, Instituto Português de Oncologia do Porto Francisco Gill E.P.E., Rua Dr. António Bernardino de Almeida, 4200-072 Porto, Portugal. ${ }^{4}$ Institute for Systems and Computer Engineering, Technology and Science, INESCTEC, Rua Dr. Roberto Frias, 4200-465 Porto, Portugal. ${ }^{5}$ Center for Health Technology and Services Research - CINTESIS, University of Porto, Rua Dr. Plácido da Costa, 4200-450 Porto, Portugal.

Received: 24 September 2019 Accepted: 12 February 2020

Published online: 21 February 2020

\section{References}

1. Saunders $C$, Sykes $N$. The management of terminal malignant disease. 3rd editio. London: Edward Arnold; 1993.

2. Beng K. The last hours and days of life: a biopsychosocial-spiritual model of care. Asia Pac Fam Med. 2004:4:1-3.

3. Sulmasy D. A biopsychosocial-spiritual model for the care of patients at the end of life. Gerontologist. 2002;42:24-33.

4. McClain-Jacobson C, Rosenfeld B, Kosinski A, Pessin H, Cimino JE, Breitbart W. Belief in an afterlife, spiritual well-being and end-of-life despair in patients with advanced cancer. Gen Hosp Psychiatry. 2004;26(6):484-6.

5. World Health Organization W. Cancer Pain Relief and Palliative Care: Report of a WHO expert committee. Geneva: Schuler SA; 1983.

6. Rego F, Pereira C, Rego G, Nunes R. The psychological and spiritual dimensions of palliative care : a descriptive systematic review review. Neuropsychiatry (London). 2018:8:484-94.

7. Lucette A, Brédart A, Vivat B, Young T. Pilot-testing the French version of a provisional European Organisation for Research and Treatment of Cancer (EORTC) measure of spiritual well-being for people receiving palliative care for cancer. Eur J Cancer Care (Engl). 2014;23(2):221-7.

8. Asgeirsdottir GH, Sigurbjornsson E, Traustadottir R, Sigurdardottir V, Gunnarsdottir S, Kelly E. In the shadow of death: existential and spiritual concerns among persons receiving palliative care. J Pastoral Care Counsel. 2014;68(1-2):4. 
9. Beng TS, Guan NC, Seang LK, Pathmawathi S, Ming MF, Jane LE, et al. The experiences of suffering of palliative care patients in Malaysia: a thematic analysis. Am J Hosp Palliat Med. 2014;31(1):45-56.

10. Narayanasamy A, Owens J. A critical incident study of nurses' responses to the spiritual needs of their patients. J Adv Nurs. 2001;4:446-55.

11. Best $M$, Butow $P$, Olver I. The doctor's role in helping dying patients with cancer achieve peace: a qualitative study. Palliat Med. 2014;28(9):1139-45.

12. Puchalski CM, Ferrel B, Viriani R, R V, Otis-Green S, Baird P, et al. Improving the quality of spiritual care as a dimension of palliative care: the report of the consensus conference. J Palliat Med. 2009;12:885-904.

13. Emblen JD. Religion and spirituality defined according to current use in nursing literature. J Prof Nurs. 1992;8:41-7.

14. Miller W, Thoresen C. Spirituality, religion, and health. An emerging research field. Am Psychol. 2003;58:24-35.

15. Koenig H, McCullough M, Larson D. Handbook of religion and health. New York: Oxford University Press; 2001.

16. Bredle JM, Salsman JM, Debb SM, Arnold BJ, Cella D. Spiritual well-being as a component of health-related quality of life: the functional assessment of chronic illness therapy—spiritual well-being scale (FACIT-Sp). Religions. 2011;2(1):77-94.

17. Ellerhorst-Ryan JM. Measuring aspects of spirituality. In: Frank-Stomborg M editor. CT Instruments or Clinical Nursing Research. Appleton and Lange; 1988. p. 141-9.

18. Long C. Cultural and spiritual considerations in palliative care. J Pediatr Hematol Oncol. 2011;33(2):96-101.

19. Chochinov HM, Krisjanson LJ, Hack TF, Hassard T, McClement S, Harlos M. Dignity in the terminally ill: revisited. J Palliat Med. 2006;9(3):666-72.

20. Chochinov H, Hack T, Hassard T, Kristjanson L, McClement S, Harlos M. Dignity in the terminally ill: a cross-sectional, cohort study. Lancet. 2002;360: 2026-30.

21. Lavoie M, Blondeau D, Picard-Morin J. The autonomy experience of patients in palliative care. J Hosp Palliat Nurs. 2011;13(1):47-53.

22. Wittmann-Vieira R, Goldim JR. Bioética e cuidados paliativos: tomada de decisões e qualidade de vida. ACTA Paul Enferm. 2012;25(3):334-9.

23. Carrese J, Rhodes L. Western bioethics on the Navajo reservation. JAMA. 1995;274:826-9.

24. Heyland D, Tranmer J, Feldman-Stewart D. End-of-life decision making in the seriously ill hospitalized patient: an organizing framework and results of a preliminary study. J Palliat Care. 2000;16:S31-4.

25. Heyland DK, Tranmer J, O'Callaghan CJ, Gafni A. The seriously ill hospitalized patient: preferred role in end-of-life decision making? J Crit Care. 2003;18(1): $3-10$.

26. Charles C, Gafni A, Whelan T. Decision-making in the physician-patient encounter: revisiting the shared treatment decision-making model. Soc Sci Med. 1999:49:651-61.

27. Zalonis $\mathrm{R}$, Slota $\mathrm{M}$. The use of palliative care to promote autonomy in decision making. Clin J Oncol Nurs. 2014;18(6):707-11.

28. Ashworth $\mathrm{P}$, Longmate M, Morrison P. Patient participation: its meaning and significance in the context of caring. J Adv Nurs. 1992;17(12):1430-9.

29. Bakitas M, Kryworuchko J, Matlock DD, Volandes AE. Palliative medicine and decision science: the critical need for a shared agenda to Foster informed patient choice in serious illness. J Palliat Med. 2011;14(10):1109-16.

30. Balboni TA, Balboni MJ. The spiritual event of serious illness. J Pain Symptom Manage. 2018;56(5):816-22.

31. Martinho MJCM, Da Silva MMMFP, Angelo M. Scale of conflict in health care decision-making: an instrument adapted and validared for the portuguese language. Rev da Esc Enferm. 2013;47(3):576-83.

32. O'Connor A. Validation of a decisional conflict scale. Med Decis Making. 1995; 15(1):25-30

33. Cohen J. Statistical power analysis for the behavioral sciences. 2nd editio ed. New York: Lawrence Erlbaum Associates; 1988

34. Bender R, Lange S. Adjusting for multiple testing - when and how? J Clin Epidemiol. 2001;54(4):343-9.

35. Pinto S, Berenguer S, Martins JC, Kolcabaf K. Cultural adaptation and validation of the Portuguese end of life spiritual comfort questionnaire in palliative care patients. Porto Biomed. 2016;1(4):147-52.

36. O'Connor A. User Manual - Decisional Conflict Scale. www.ohri.ca/ decisionaid. 1993

37. Peterman AH, Fitchett G, Min D, Brady MJ, et al. Measuring spiritual wellbeing in people with cancer : the functional assessment of chronic illness therapy — spiritual well-being scale ( FACIT-Sp ) sign in Oxford academic account Society of Behavioral Medicine members sign in via your institution short. Ann Behav Med. 2002;24(1):49-58.

38. Pereira FMP, de B Santos CSV. Estudo de adaptação cultural e validação da Functional Assessment of Cancer Therapy-General em cuidados paliativos. Rev Enferm (Lisboa). 2011;ill(5):45-54.

39. Visser A, Garssen B, Vingerhoets A. Spirituality and well-being in cancer patients : a review psycho-oncology abstract. Psychooncology. 2010; 19(November 2009):565-72.

40. Alase A. The interpretative phenomenological analysis (IPA): a guide to a good qualitative research approach. Int J Educ Lit Stud. 2017;5(2):9.

41. Song MK, Sereika SM. An evaluation of the decisional conflict scale for measuring the quality of end-of-life decision making. Patient Educ Couns. 2006;61(3):397-404

42. Koedoot N, Molenaar S, Oosterveld P, Bakker P, De Graeff A, Nooy M, et al The decisional conflict scale: further validation in two samples of Dutch oncology patients. Patient Educ Couns. 2001;45(3):187-93.

43. Mystakidou K, Tsilika E, Parpa E, Hatzipli I, Smyrnioti M, Galanos A, et al. Demographic and clinical predictors of spirituality in advanced cancer patients: a randomized control study. J Clin Nurs. 2008;17(13):1779-85.

44. Harding R, Powell RA, Namisango E, Merriman A, Gikaara N, Ali Z, et al. Palliative care-related self-report problems among cancer patients in East Africa: a two-country study. Support Care Cancer. 2014;22(12):3185-92.

45. Wentlandt K, Burman D, Swami N, Hales S, Rydall A, Rodin G, et al. Preparation for the end of life in patients with advanced cancer and association with communication with professional caregivers. Psychooncology. 2011;876(June 2011):868-76.

46. Hui D, de la Cruz M, Thorney S, Parsons HA, Delgado-Guay M, Bruera E. The frequency and correlates of spiritual distress among patients with advanced Cancer admitted to an acute palliative care unit. Am J Hosp Palliat Med. 2011; 28(4):264-70.

47. Bovero A, Leombruni P, Miniotti M, Rocca G, Torta R. Spirituality, quality of life, psychological adjustment in terminal cancer patients in hospice. Eur J Cancer Care (Engl). 2016;25(6):961-9.

48. Elsner F, Schmidt J, Rajagopal M. al et. Psychosocial and spiritual problems of terminally ill patients in Kerala, India. Future Oncol. 2012;8(9):1183-91.

49. Selman L, Speck P, Gysels M, Agupio G, Dinat N, Downing J, et al. 'Peace' and 'life worthwhile' as measures of spiritual well-being in African palliative care: a mixed-methods study. Health Qual Life Outcomes. 2013;11(1):94.

50. Fegg MJ, Brandstätter M, Kramer M, Kögler M, Haarmann-Doetkotte S, Borasio GD. Meaning in life in palliative care patients. J Pain Symptom Manage. 2010;40(4):502-9.

51. Rabow MW, Knish SJ. Spiritual well-being among outpatients with cancer receiving concurrent oncologic and palliative care. Support Care Cancer. 2015;23(4):919-23.

52. Buxton F. Spiritual distress and integrity in palliative and non-palliative patients. Br J Nurs. 2007:16(15):920-4.

53. Gielen J, Bhatnagar S, Chaturvedi SK. Prevalence and nature of spiritual distress among palliative care patients in India. J Relig Health. 2017;56(2):530-44.

54. Ai AL, Hopp F, Tice TN, Koenig H. Existential relatedness in light of eudemonic well-being and religious coping among middle-aged and older cardiac patients. J Health Psychol. 2013;18(3):368-82.

55. Ano G, Vasconcelles E. Religious coping and psychological adjustment to stress: a meta-analysis. J Clin Psychol. 2005;61(4):461-80.

56. Phelps AC, Maciejewski PK, Nilsson M, Tracy A, Wright AA, Paulk ME, et al. Association between religious coping and use of intensive life-prolonging care near death among patients with advanced care. JAMA. 2010;301(11): 1140-7.

57. Kernohan WG, Waldron M, McAfee C, Cochrane B, Hasson F. An evidence base for a palliative care chaplaincy service in Northern Ireland. Palliat Med. 2007;21(6):519-25.

58. Francoeur RB, Payne R, Raveis VH, Shim H. Palliative care in the Inner City: patient religious affiliation, underinsurance, and symptom attitude. Cancer. 2007:109(2 SUPPL):425-34

59. Wachholtz A, Pearce M. Does spirituality as a coping mechanism help or hinder coping with chronic pain. Curr Pain Headache Rep. 2009;13:127-32.

60. Hills J, Paice J, Cameron J, et al. Spirituality and Distress in Palliative Care Consultation. J Palliat Med. 2005;8(4):782-8.

61. Mystakidou K, Tsilika E, Parpa E, Smyrnioti M, Vlahos L. Assessing Spirituality and Religiousness in Advanced Cancer Patients. Am J Hosp and Palliat Med. 2007;23(6):457-63. 
62. Strawbridge W, Shema S, Cohen R, Roberts R, Kaplan G. Religiosity buffers effects of some stressors on depression but exacerbates others. J Gerontol B Psychol Sci Soc Sci. 1998;53:118-26.

63. Carone DJ, Barone D. A social cognitive perspective on religious beliefs: their functions and impact on coping and psychotherapy. Clin Psychol Rev. 2001;21:989-1003.

64. Stefanek M, McDonald PG, Hess SA. Religion, spirituality and cancer: current status and methodological challenges. Psychooncology. 2005;14(6):450-63.

65. Cotton S, Levine E, Fitzpatrick C, Dold K, Targ E. Exploring the relationships among spiritual well-being, quality of life, and psychological adjustment in women with breast cancer. Psychooncology. 1999;8:429-38.

66. Fitchett $\mathrm{G}$, Canada $A$. The role of religion/spirituality in coping with cancer Evidence, assessment, and intervention. In: Holland J, Breitbart W, Jacobsen P, editors. Psychooncology. 2nd editio ed. New York: Oxford University Press; 2010. p. 440-6.

67. Szaflarski M, Ritchey P, Leonard A, Mrus J, Peterman A, Ellison C, et al. Modeling the effects of spirituality/religion on patients' perceptions of living with HIV/AIDS. J Gen Intern Med. 2006;21:28-38.

68. Bélanger $E$, Rodríguez C, Groleau D, Légaré F, Macdonald ME, Marchand R. Initiating decision-making conversations in palliative care: An ethnographic discourse analysis. BMC Palliat Care. 2014;13(1):63.

69. Murray SA, Kendall M, Grant E, Boyd K, Barclay S, Sheikh A. Patterns of social, psychological, and spiritual decline toward the end of life in lung Cancer and heart failure. J Pain Symptom Manage. 2007;34(4): 393-402.

70. Kandasamy A, Chaturvedi S, Desai G. Spirituality, distress, depression, anxiety, and quality of life in patients with advanced cancer. Indian J Cancer. 2011;48(1):55.

71. Mystakidou K, Tsilika E, Parpa E, Pathiaki M, Patiraki E, Galanos A, et al. Exploring the relationships between depression, hopelessness, cognitive status, pain, and spirituality in patients with advanced Cancer. Arch Psychiatr Nurs. 2007;21(3):150-61.

72. Perkins EA, Small BJ, Balducci L, Extermann M, Robb C, Haley WE. Individual differences in well-being in older breast cancer survivors. Crit Rev Oncol Hematol. 2007;62(1):74-83.

73. Yong J, Kim J, Han SS, Puchalski CM. Development and validation of a scale assessing spiritual needs for Korean patients with cancer. J Palliat Care. 2008;24(4):240-6.

74. Young WC, Nadarajah SR, Skeath PR, Berger AM. Spirituality in the context of life-threatening illness and life-transforming change. Palliat Support Care. 2015;13(03):653-60.

75. Dobratz MC. "All my saints are within me": expressions of end-of-life spirituality. Palliat Support Care. 2013;11(03):191-8.

76. Noble H, Brazil K, Burns A, Hallahan S, Normand C, Roderick P, et al. Clinician views of patient decisional conflict when deciding between dialysis and conservative management: qualitative findings from the PAlliative care in chronic kidney diSease (PACKS) study. Palliat Med. 2017;31(10):921-31.

77. Kalkjian L, Jekel J, Friedland G. End-of-life decision in HIV-positive patients: the role of spiritual beliefs. AIDS. 1998;12:103-7.

78. Kruse B, Ruder S, Martin L. Spirituality and coping at the end of life. J Hosp Palliat Nurs. 2007:9:296-304.

79. Park C. The meaning making model: a framework for understanding meaning, spirituality, and stress-related growth in health psychology. Eur Heal Psychol. 2013;2:40-7.

80. Moss E, Dobson K. Psychology, spirituality and end-of-life care: an ethical integration? Can Psychol. 2006;47:284-99.

81. Rego F, Nunes R. The spiritual advocate in palliative care. J Palliat Care Med. 2016;6(5):1000283.

82. Beauchamp T, Childress J. Principles of biomedical ethics. 7th editio ed. New York: Oxford University Press; 2012.

83. Harris J. The value of life. An introduction to medical ethics. London: Routledge; 1991.

84. Saunders C. The evolution of palliative care. Patient Educ Couns. 2000;41(1):7-13.

85. Kierzek G, Rac $\vee$, Pourriat JL. Advance directives and surrogate decision making before death. N Engl J Med. 2010;363(3):295-6.

86. Seibel K, Valeo SC, Xander C, Adami S, Duerk T, Becker G. Terminally ill patients as customers: the Patient's perspective. J Palliat Med. 2013;17(1):11-7.

87. Puchalski CM. Spirituality and end-of-life care: a time for listening and caring. J Palliat Med. 2002;5:289-94.

88. Rego F, Nunes $R$. The interface between psychology and spirituality in palliative care. J Health Psychol. 2019;24(3):279-87.
89. Martin G. Empowerment of dying patients: the strategies and barriers to patient autonomy. J Adv Nurs. 1998;28(4):737-44.

\section{Publisher's Note}

Springer Nature remains neutral with regard to jurisdictional claims in published maps and institutional affiliations.

\section{Ready to submit your research? Choose BMC and benefit from:}

- fast, convenient online submission

- thorough peer review by experienced researchers in your field

- rapid publication on acceptance

- support for research data, including large and complex data types

- gold Open Access which fosters wider collaboration and increased citations

- maximum visibility for your research: over $100 \mathrm{M}$ website views per year

At BMC, research is always in progress.

Learn more biomedcentral.com/submissions 